\title{
Neben dem Internet bleiben Printmedien unverzichtbar
}

Die „Neue Grippe“ hat bereits zum Zeitpunkt des Verfassens dieser Zeilen Deutschland fest im Griff. Die Diskussion um den Impfstoff, die Notwendigkeit der Impfung und besonders der Kostenaspekt sind noch ungeklärt, aber möglicherweise sind die offenen Fragen beim Erscheinen dieser Ausgabe der Flugmedizin Tropenmedizin Reisemedizin bereits beantwortet. Es wäre gut, wenn der Gesetzgeber und die Kostenträger kein anderes Vorgehen planen als bei der „Alten Grippe“. Denn auch die saisonale Grippe wird wieder auf uns zukommen und eventuell müssen gefährdete Personen doppelt geimpft werden - dies darf nicht in Vergessenheit geraten.

Der Herbst ist jedoch nicht nur die Zeit der Infektionskrankheiten, sondern auch die Zeit, die als typische Wandersaison gilt. Die Menschen zieht es in die Alpen, aber das Spätjahr markiert auch den Beginn der Trekkingsaison in den asiatischen Zielen. Wer dorthin reist, sollte sich auf den Internetseiten der herausgebenden Fachgesellschaften informieren, welche Präventionsmaßnahmen notwendig sein können. Wer weit und hoch hinaus will, kann sich auf den Internetseiten der BExMed über Präventionsmaßnahmen zu den Bergkrankheiten informieren.

Das Internet ist inzwischen eine unverzichtbare Quelle der Information geworden, ohne die die Tätigkeit der beratenden Ärzte deutlich schwieriger wäre. Ich erinnere mich noch sehr gut daran, wie ich gemeinsam mit Tomas Jelinek im Jahre 1999 eine Vortragssitzung zum Thema „Reisemedizin im Internet“ organisierte. Dieses Thema würde heute niemanden mehr anlocken, auch wenn ein paar der damals angesprochenen Probleme bis in die Gegenwart gültig sind. Denn auch heute ist oft unklar, wer hinter den Informationen im Netz steckt, wie sie zustande gekommen sind und wer sie überprüft hat. Daher wird sich jeder inzwischen „seine“ Quellen im Netz gesucht haben, denen er vermutlich vertrauen kann.

Trotzdem bleiben aus meiner Sicht Zeitschriften wie die Ihnen vorliegende Flugmedizin Tropenmedizin Reisemedizin unverzichtbar, um sich breiter zu informieren. Denn nur in Zeitschriften und Büchern findet man, wonach man bei den Suchmaschinen im Internet eben nicht explizit gefahndet hat und erweitert so seinen Horizont. Daher möchte ich Sie hiermit auch ermuntern, den gedruckten Medien treu zu bleiben und sich an der Vielfalt der Themen in diesem Heft zu erfreuen.

\section{Mit herzlichen Grüßen,}

PD Dr. Rainald Fischer, München

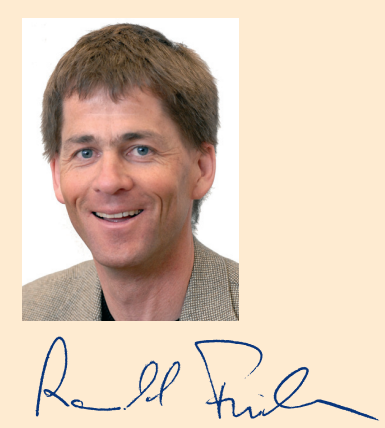

PD Dr. Rainald Fischer, München 